\title{
Prepulse Inhibition of Startle Response: Recent Advances in Human Studies of Psychiatric Disease
}

\author{
Hidetoshi Takahashi ${ }^{1,2}$, Ryota Hashimoto ${ }^{2,3,4}$, Masao Iwase ${ }^{2}$, Ryouhei Ishii ${ }^{2}$, Yoko Kamio ${ }^{1}$, Masatoshi Takeda \\ 'Department of Child and Adolescent Mental Health, National Institute of Mental Health, National Center of Neurology and Psychiatry, \\ Tokyo, ${ }^{2}$ Department of Psychiatry, Osaka University Graduate School of Medicine, Osaka, ${ }^{3}$ CREST (Core Research for Evolutionary Science \\ and Technology), JST (Japan Science and Technology Agency), Saitama, ${ }^{4}$ Molecular Research Center for Children's Mental Development, \\ United Graduate School of Child Development, Osaka University, Kanazawa University and Hamamatsu University School of Medicine, \\ Osaka, Japan
}

\begin{abstract}
Prepulse inhibition (PPI) is considered to be one of the most promising neurophysiological indexes for translational research in psychiatry. Impairment of PPI has been reported in several psychiatric diseases, particularly schizophrenia, where PPI is considered a candidate intermediate phenotype (endophenotype) of the disease. Recent findings from a variety of research areas have provided important evidence regarding PPI impairment. Human brain imaging studies have demonstrated the involvement of the striatum, hippocampus, thalamus and frontal and parietal cortical regions in PPI. In addition, several genetic polymorphisms, including variations in the genes coding for Catechol O-methyltransferase, Neuregulin 1, nuclear factor kappa-B subunit 3 and serotonin-2A receptor were related to PPI; and these findings support PPI as a polygenetic trait that involves several neurotransmitter pathways. Early psychosis studies suggest that PPI disruption is present before the onset of psychosis. Also, discrepancy of PPI impairment between children and adults can be found in other psychiatric diseases, such as autistic spectrum disorders and posttraumatic stress disorder, and comprehensive investigation of startle response might contribute to understand the impairment of the neural circuitry in psychiatric diseases. Finally, recent studies with both Asian and Caucasian subjects indicate that patients with schizophrenia exhibit impaired PPI, and impaired sensorimotor gating might be a global common psychophysiological feature of schizophrenia. In conclusion, studies of PPI have successfully contributed to a better understanding of the fundamental neural mechanisms underlying sensorimotor gating and will certainly be most valuable in devising future approaches that aim to investigate the complex pathogenesis of psychiatric diseases.
\end{abstract}

KEY WORDS: Endophenotypes; Mental disorders; Psychophysiology; Schizophrenia; Startle reaction.

\section{INTRODUCTION}

To understand the complex pathogenesis of genetic and environmental interaction underlying psychiatric disease has been set as a critical goal, as hopes on translational research that combines both basic and clinical researchers have soared.

Prepulse inhibition (PPI) is considered to be one of the most promising neurophysiological indexes for translational research in psychiatry. Impairment of PPI is re-

\footnotetext{
Received: September 20, 2011 / Revised: November 18, 2011

Accepted: November 21, 2011

Address for correspondence: Hidetoshi Takahashi, MD, PhD Department of Child and Adolescent Mental Health, National Institute of Mental Health, National Center of Neurology and Psychiatry, 4-1-1 Ogawahigashicho, Kodaira, Tokyo 1878553 , Japan

Tel: +81-42-341-2711, Fax: +81-42-346-1944

E-mail: htakahashi@ncnp.go.jp
}

ported in several psychiatric diseases, ${ }^{1)}$ of which schizophrenia is the most prominent. Other diseases include anxiety disorders, such as obsessive-compulsive disorder (OCD) and posttraumatic stress disorder (PTSD), and developmental disorders, such as autistic spectrum disorders (ASD).

Although PPI is a well established index, ${ }^{2-5)}$ there is still a vast number of research areas where the potential beneficial use of PPI has not been investigated. In this review, we briefly overview the well described applications of PPI and then discuss some recent advances in human PPI studies, including research on brain imaging, genetic analyses and comparison of PPI in different populations, at different ages. 


\section{A BRIEF OVERVIEW OF PPI IN HUMAN SUBJECTS}

PPI is usually defined as a reduction of the startle reflex due to weak sensory prestimulation. ${ }^{6}$ PPI is considered to be the most common psychophysiological index of sensorimotor gating, which is an autonomic inhibition system that regulates sensory input by filtering out irrelevant or distracting stimuli. This prevents overflow of sensory information and allows for the selective and efficient processing of relevant information. ${ }^{6-8)}$ PPI is elicited by any kind of stimuli, including visual, acoustic, tactile or olfactory stimuli. Acoustic stimuli are usually used for experiments, and the majority of human studies measure orbicularis oculi muscle electromyographic activity of blink reflex induced by acoustic startle stimuli. ${ }^{9)}$ As PPI can be assessed using simple nonlinguistic stimuli, PPI is widely investigated across races ${ }^{10-12)}$ and species (animals, ${ }^{3-5,13-15)}$ such as rats or mouse), using similar experimental paradigms.

Although PPI is considered to be a stable index of individual sensorimotor gating, ${ }^{16)}$ several factors can affect its measurement. Some of the most relevant include gender, smoking and medication, in particular antipsychotic medication. Gender-related differences in PPI have been reported in normal subjects, with levels of PPI in women lower than in men. ${ }^{17-24)}$ In addition, women present fluctuations of PPI across the menstrual cycle, ${ }^{25)}$ with the lowest levels manifested in the mid-luteal phase. ${ }^{18)}$ PPI can also be enhanced by smoking ${ }^{26-29)}$; however, this effect appears to be of short term duration (less than 10 minutes). ${ }^{21)}$ Some studies also reported the effects of substances such as caffeine, ${ }^{30,31)}$ cannabis, ${ }^{32,33)}$ and amphetamines, ${ }^{34,35)}$ on PPI. Finally, PPI is considered to be affected by the medication status and to involve several neurotransmitter pathways, ${ }^{2,36-39)}$ including the dopaminergic, glutamatergic, serotonergic and cholinergic pathways. This will be a matter of further discussion in the following sections.

\section{PPI IN SCHIZOPHRENIA}

Schizophrenia is one of the most prominent psychiatric diseases presenting deficits in PPI. Impaired sensorimotor gating has been considered to be a common psychophysiological feature of schizophrenia that may, theoretically, lead to severe dysfunctions in perception, attention and thinking. ${ }^{40,41)}$ Since Braff et al. ${ }^{6)}$ reported PPI reduction in schizophrenic patients, that reductions of PPI have been consistently demonstrated in schizophrenia., ${ }^{2,38,42)}$
Recently, PPI has been considered a promising candidate intermediate phenotype (endophenotype) of schizophrenia. ${ }^{43-46)}$ PPI is not only reduced in schizophrenia patients but also in unaffected relatives, ${ }^{47,48)}$ and it has showed substantial heritability of $32-50 \%{ }^{45,49,50)}$ Deficient PPI has also been observed in patients with schizotypal personality disorder ${ }^{47,51,52)}$ and, to a lesser extent, in normal participants scoring high on psychometric measures of psychosis proneness. ${ }^{53-55)}$ Although the profile of startle measures is thought to differ across races, ${ }^{10-12)}$ patients with schizophrenia consistently had reduced PPI compared to normal controls in recent studies with Asian subjects. ${ }^{56-58)}$

Numerous studies have provided evidence that PPI deficits in patients with schizophrenia are improved by antipsychotics, ${ }^{24,37,38,40,42,59-67)}$ in particular atypical antipsychotics, which appear to have a close association with PPI improvement in schizophrenia. ${ }^{24,42,59-61,63,64,66,68-70)}$ Although PPI has been reported in association with positive symptoms ${ }^{65,71)}$ and negative symptoms, ${ }^{71,72)}$ thought disorders $^{73)}$ and social perception ${ }^{74)}$ of schizophrenia, most studies do not support a link between PPI and psychiatric symptoms. $^{24,63,70,75)}$ However, this might be explained by the medication status of the patients, which is known to affect the relationship of psychiatric symptoms with PPI in schizophrenia. ${ }^{76)}$ While antipsychotic-naive schizophrenia patients ${ }^{65,68,77-80)}$ present PPI deficits, antipsychotic medication eliminates the impairment of PPI. ${ }^{78,79)}$ Vollenweider et $a l .{ }^{81)}$ has suggested that clozapine enhances PPI in healthy humans with low but not with high PPI levels. On the other hand, haloperidol failed to increase PPI in subjects exhibiting low levels of PPI, despite the fact that PPI was attenuated in those subjects with high sensorimotor gating levels. ${ }^{82)}$ Therefore, the effect of antipsychotics on PPI might differ depending on the medication or the severity of the PPI deficits. ${ }^{81,82)}$ Longitudinal studies evaluating PPI before and after medication will help to elucidate the effect of antipsychotics on PPI in schizophrenia.

\section{BRAIN AREAS INVOLVED IN PPI}

In order to comprehend the physiological nature of PPI it is necessary to investigate the areas of the brain that are required during PPI. In experimental animals, ${ }^{37,40,83)}$ the cortico-striato-pallido-thalamic circuitry is thought to be responsible for modulation of PPI. A recent study ${ }^{84)}$ has shown that some forebrain areas are involved in top-down modulation of PPI. Recently, human brain imaging stud- 
ies of PPI using several approaches, such as positron emission tomography and anatomical/functional magnetic resonance imaging (MRI), provided important evidence to understand the neurophysiological mechanisms of PPI.

The Kumari et $a l .{ }^{85)}$ research group has published numerous important studies that addressed the biological nature of PPI. In an MRI volumetric voxel-based morphometry study, healthy subjects showed significant positive correlations between PPI and grey matter volume in the hippocampus extending to parahippocampal gyrus, basal ganglia, including parts of putamen, globus pallidus, and nucleus accumbens, superior temporal gyrus, thalamus, and inferior frontal gyrus. Patients with schizophrenia ${ }^{86}$ showed significantly positive correlations between PPI and grey matter volume in the dorsolateral prefrontal, middle frontal and the orbital/medial prefrontal cortices. Functional MRI (fMRI) studies ${ }^{87,88)}$ showed that the PPI of healthy subjects was associated with increased activation in the striatum extending to hippocampus and thalamus, inferior frontal and inferior parietal regions, and that all activated regions had significantly greater response in healthy subjects than schizophrenic patients. ${ }^{88)}$ Patients treated with risperidone or olanzapine, but not with typical antipsychotics, showed significant activation in the PPIrelevant regions. ${ }^{87)}$

Other research groups have found similar results. In an fMRI study of Campbell et al. ${ }^{89)}$ PPI was found associated with activation in pons, thalamus, caudate nuclei, left angular gyrus and bilaterally in anterior cingulate. Also by fMRI, Hazlett et al. ${ }^{90)}$ showed that, using attend/ignore PPI paradigm, lower left caudate activation during the attended PPI condition was associated with more deficient sensorimotor gating among schizotypal personality disorder, schizophrenia, and healthy controls. In a PET ${ }^{91)}$ study, normal controls showed a positive association between PPI and metabolic activity rates of glucose in prefrontal (Brodmann's areas 8, 9, and 10 bilaterally) and lower in visual cortex, while patients only showed this association for area 10 in the left hemisphere.

These findings demonstrate the involvement of the striatum, hippocampus, thalamus, and frontal and parietal cortical regions in PPI. Dysfunctions in any of these regions may underlie observations of reduced PPI in psychiatric diseases, including schizophrenia, which might be improved by atypical antipsychotic medication.

\section{GENETIC BASIS OF PPI}

The use of PPI as an endophenotype in schizophrenia has been recently becoming consensual. ${ }^{44,46,92)}$ As PPI can be easily measured, it has the advantage to collect large sample sizes necessary for genetic approaches that conduct multi-site studies. ${ }^{12)}$ Several research groups have been investigating the relationship between PPI and the genome.

Roussos et al. and Giakoumaki et al..$^{93-96)}$ have reported associations of PPI with several genotypes in healthy males. Examination of the Catechol O-methyltransferase (COMT) Val158Met polymorphism, ${ }^{93)}$ the main catabolic pathway of released dopamine (DA) in the prefrontal cortex (PFC), showed that Val (low PFC DA)/Val individuals had the lowest PPI, Met (high PFC DA)/Met the highest, and $\mathrm{Val} / \mathrm{Met}$ were intermediate. In addition, the nonstimulant COMT inhibitor tolcapone increased PPI significantly in the Val/Val group and tended to have the opposite effect in the Met/Met group. ${ }^{94)}$ In a study examining the influence of the Dopamine D3 receptor Ser9Gly polymorphism on human PPI, ${ }^{95)}$ Gly/Gly individuals had the lowest PPI and Ser/Ser individuals had the highest PPI, while Ser/Gly individuals were intermediate. Investigation of the relationship between PPI and haplotypes comprising three Proline dehydrogenase (oxidase 1) single nucleotide polymorphisms (SNPs; 1945T/C, 1766A/G, $1852 \mathrm{G} / \mathrm{A}$ ) located in the 3 ' region of the gene, ${ }^{96)}$ CGA carriers, which are preferentially transmitted in schizophrenia patients, ${ }^{97,98)}$ exhibited attenuated PPI compared with the noncarriers. Furthermore, Roussos et al. examined the relevance for PPI of SNPs in promising schizophrenia risk genes, such as the $\mathrm{D}$-amino acid oxidase (DAO) gene (rs4623951, rs2111902, rs3918346, rs3741775, and rs382525199) and the Neuregulin 1 (NRG1) gene (rs6994992, SNP8NRG221132, SNP8NRG241930, rs3924999, rs2439272 and rs10503929), ${ }^{100)}$ and reported that reduced PPI was associated to the rs4623951 T-rs3741775_G and rs4623951_T-rs2111902_T diplotypes of $D A O$ gene, ${ }^{-99)}$ and to the SNP8NRG241930 G allele and particularly the rs6994992 $\mathrm{T}$ allele and rs $2439272 \mathrm{C}$ allele NRG1 gene. ${ }^{100)}$

The laboratory of Quednow et al. ${ }^{101-103)}$ has reported associations of PPI with several genotypes in both healthy subjects and patients with schizophrenia. An association of PPI with the serotonin-2A receptor $\left(5-H T_{2 A} R\right)$ A1438G/T102C (rs6311/rs6313), COMT Val158Met (rs4680) and NRG1 Arg38Gln (rs3924999) were investigated in healthy Caucasian subjects, ${ }^{101)}$ and increased PPI levels were found in homozygous for the $5-H T_{2 A} R$ T102C-T/A-1438 G-A allele. Increased PPI levels were also found in male subjects with the COMT Met158Met- 
genotype, but no significant association of PPI with the $N R G 1$ Arg38Gln genotype was detected. Investigation of the impact of three $5-H T_{2 A} R$ polymorphisms (A-1438G, $\mathrm{T} 102 \mathrm{C}, \mathrm{H} 452 \mathrm{Y}$ ) on PPI in Caucasian schizophrenia patients ${ }^{102)}$ showed that patients carrying the T102C TT and the A-1438G AA allele present significantly higher PPI levels compared with all other variants. In contrast, the H452Y polymorphism did not affect PPI. Quednow et $a l .{ }^{103)}$ also investigated the impact of the COMT Val158Met polymorphisms on PPI in Caucasian schizophrenic inpatients, and reported that patients carrying the Met/Met allele showed elevated PPI levels compared to other two genotypes. PPI was also influenced by two common nicotinic acetylcholine receptor (nAChR) $\alpha 3$ subunit (CHRNA3) polymorphism (rs1051730/rs1317286) in healthy subjects and in patients with schizophrenia. ${ }^{104)}$ Recently, ${ }^{105}$ ) the impact of the transcription factor 4 (TCF4) gene (rs9960767), a susceptibility gene for schizophrenia, on PPI was investigated in healthy subjects and in a schizophrenia spectrum group (including schizophrenia patients and individuals at high risk for schizophrenia), and in both samples PPI was strongly decreased in carriers of the schizophrenia risk allele $\mathrm{C}$ of the TCF4 gene.

Hong et al. ${ }^{106)}$ examined the effects of the NRG1 Arg38Gln polymorphism on PPI in patients with schizophrenia and in normal controls. They reported that PPI was lowest in the subjects who were homozygous for the minor allele $\mathrm{A} / \mathrm{A}$ carriers, intermediate in $\mathrm{A} / \mathrm{G}$ carriers and highest in homozygous major alleles $\mathrm{G} / \mathrm{G}$ carriers in both patient and control groups. Greenbaum et al. ${ }^{107)}$ reported an association of the reelin SNP rs7341475 with PPI. In addition, Hokyo et al. ${ }^{108)}$ reported that, in both healthy subjects and patients with schizophrenia, human N-methyl-D-aspartate (NMDA) receptor 2B subunit gene (GRIN2B) polymorphism rs1019385 (T200G) did not show any significant influence on PPI, although it was significantly related to habituation of startle response. Finally, Hashimoto et al. ${ }^{109)}$ reported that PPI deficits in schizophrenia were associated with PPI schizophrenia risk genotypes of three SNPs (rs11820062, rs2306365, rs7119750) in the v-rel avian reticuloendotheliosis viral oncogene homolog A gene, which encodes the major component of the Nuclear factor kappa B (NF- $\kappa$ B) complex.

All together, these data strongly support PPI as a polygenetic trait that involves several neurotransmitter pathways and the use of PPI as a valid schizophrenia endophenotype. However, as noted previously, PPI can be affected by several factors, such as gender, smoking status and antipsychotic medication, and future studies with large sample sizes that consider these effects are deemed required. Investigation of mechanism how these factors effect on PPI across genotypes will contribute to a better understanding of the fundamental neural mechanisms underlying sensorimotor gating and will certainly be most valuable in devising future approaches that aim to investigate the complex pathogenesis of psychiatric diseases.

\section{EARLY PSYCHOSIS AND PPI}

Research on early psychosis (ER) has been growing and PPI might also play an important role in this field.

In a 2-year follow-up study, ${ }^{110)}$ comparing ultra-high risk (UHR) adolescents with matched control group, UHR individuals showed reduced PPI at both baseline and 2 years compared with controls. Clinical improvement in UHR individuals was associated with an increase in PPI parameters. In another study, ${ }^{111)}$ PPI of acoustic startle response was assessed in subjects with prodromal symptoms of schizophrenia, first-episode schizophrenia patients and healthy control subjects. Prodromal subjects and unmedicated patients with first-episode schizophrenia showed significant PPI deficits, whereas schizophrenia patients treated with risperidone had almost normal PPI. These studies, together with the evidence that antipsychotic-naive schizophrenia patients ${ }^{65,68,77-80)}$ present PPI impairment, suggest that PPI disruption might be already present before the onset of psychosis and that PPI may represent a vulnerability marker for psychosis.

Intriguing results were found in a study ${ }^{112}$ investigating PPI in EP, at risk (AR) for psychosis and comparison subjects at baseline and 6 months later. PPI was stable with repeated assessment and EP subjects had reduced PPI. The unexpected findings regard the fact that medication-naive EP subjects, as well as AR subjects who later developed psychosis, had greater PPI compared to EP subjects with antipsychotic medication, and to AR subjects who did not develop psychosis, respectively, introducing the possibility of early compensatory changes that diverge from findings in chronic patients. Therefore, longitudinal studies following up the pathological change of startle modulation in a long period prior to the onset of the disease are required to determine the use of PPI for early detection of psychosis. 


\section{PPI IN CHILDREN AND DEVELOPMENTAL DISORDERS}

Startle modulation is not consistent through children to adults. The neurophysiological mechanisms of PPI are considered to undergo development during early childhood and do not mature until about 8 years of age in both male and female subjects. ${ }^{113,114)}$

Several studies have revealed PPI impairment in children with psychiatric disease, such as the $22 \mathrm{q} 11$ deletion syndrome, ${ }^{115)}$ Tourette's syndrome ${ }^{116)}$ and primary nocturnal enuresis. ${ }^{117)}$ On the other hand, children with autism, ${ }^{118,119)}$ attention deficit hyperactivity disorder (ADHD), ${ }^{120,121)}$ PTSD, ${ }^{122)}$ did not show PPI deficits (in traditional PPI experimental paradigm).

It should be noted that discrepancy in PPI between children and adults can be found in some psychiatric diseases. For instance, although children with autism did not ${ }^{118,119)}$ show PPI deficits, adults with ASD, such as autism ${ }^{123)}$ or Asperger's syndrome, ${ }^{124)}$ presented PPI impairments. Adults with PTSD also exhibited PPI deficits, ${ }^{125,126)}$ while children ${ }^{122)}$ or adolescent ${ }^{127)}$ with PTSD did not. The neurophysiological development related to PPI of startle response might not be relevant for some psychiatric diseases, such as ADHD, which did not exhibit PPI impairment in both children ${ }^{120,121)}$ and adults, ${ }^{128,129)}$ but might affect the discrepancy in PPI impairment between children and adults in other diseases, such as ASD or PTSD. Although PPI did not differ significantly between children with autism and normal age-matched controls, PPI of some controls were not evaluated, since they were rejected from the study for reasons such as drowsiness or small response. ${ }^{119)}$ Patients with autism are known to have hyperacusia, and they might present a lower threshold of startle and elicit startle by weak stimuli which might not elicit startle in normal controls. It is important to determine an experimental paradigm which can assess sensorimotor gating in both children with ASD and typical development. Although PPI impairment is not apparent in children with autism, there might be deficits in the mechanism of startle response in children with ASD which would develop to PPI impairment when they become adults, and comprehensive investigation of startle response, including threshold to elicit startle, startle magnitude, as well as PPI, might contribute to uncover the impairment of the neural circuitry in autism. There are several attempts to develop experimental paradigm of PPI, ${ }^{114,130-135)}$ including attentional modulation of PPI, ${ }^{114,132-135)}$ and application of these paradigms might in- form neurobiological basis underpinning PPI deficits in both children and adults with ASD.

\section{CONCLUSION}

PPI is a well-established neurophysiological index for translational research in psychiatric diseases. Recent studies from a variety of research areas all over the world have provided us important evidence to understand the neural mechanisms of sensorimotor gating, assessed by PPI. These findings will be most valuable in devising future studies that aim at investigating and understanding the complex pathogenesis of psychiatric diseases.

\section{Acknowledgments}

The authors gratefully thank Dr. Young-Chul Chung for inviting us to publish this review and Dr. Antonio Currais for editorial review.

This work was supported in part by Grants-in-Aid from the Japanese Ministry of Health, Labor and Welfare (H18-kokoro-005, H19-kokoro-002), the Japanese Ministry of Education, Culture, Sports, Science and Technology (17591211, 18689030, 20591402, 21791130, 23890257), Intramural Research Grant (23-1) for Neurological and Psychiatric Disorders of NCNP, CREST of JST, Japan Foundation for Neuroscience and Mental Health, and Mitsubishi Pharma Research Foundation. The study sponsors had no further role in the study design; in the collection, analysis and interpretation of data; in the writing of the report; and in the decision to submit the paper for publication.

\section{REFERENCES}

1. Geyer MA. The family of sensorimotor gating disorders: comorbidities or diagnostic overlaps? Neurotox Res 2006; 10:211-220.

2. Swerdlow NR, Weber M, Qu Y, Light GA, Braff DL. Realistic expectations of prepulse inhibition in translational models for schizophrenia research. Psychopharmacology (Berl) 2008;199:331-388.

3. Fitch RH, Threlkeld SW, McClure MM, Peiffer AM. Use of a modified prepulse inhibition paradigm to assess complex auditory discrimination in rodents. Brain Res Bull 2008;76:1-7.

4. Li L, Du Y, Li N, Wu X, Wu Y. Top-down modulation of prepulse inhibition of the startle reflex in humans and rats. Neurosci Biobehav Rev 2009;33:1157-1167.

5. Powell SB, Zhou X, Geyer MA. Prepulse inhibition and genetic mouse models of schizophrenia. Behav Brain Res 2009;204:282-294.

6. Braff D, Stone C, Callaway E, Geyer M, Glick I, Bali L. Prestimulus effects on human startle reflex in normals and schizophrenics. Psychophysiology 1978;15:339-343. 
7. Braff DL, Grillon C, Geyer MA. Gating and habituation of the startle reflex in schizophrenic patients. Arch Gen Psychiatry 1992;49:206-215.

8. Geyer MA, Braff DL. Startle habituation and sensorimotor gating in schizophrenia and related animal models. Schizophr Bull 1987;13:643-668.

9. Blumenthal TD, Cuthbert BN, Filion DL, Hackley S, Lipp $\mathrm{OV}$, van Boxtel A. Committee report: Guidelines for human startle eyeblink electromyographic studies. Psychophysiology 2005;42:1-15.

10. Hasenkamp W, Norrholm SD, Green A, Lewison B, Boshoven W, Keyes M, et al. Differences in startle reflex and prepulse inhibition in European-Americans and African-Americans. Psychophysiology 2008;45:876-882.

11. Swerdlow NR, Talledo JA, Braff DL. Startle modulation in Caucasian-Americans and Asian-Americans: a prelude to genetic/endophenotypic studies across the 'Pacific Rim'. Psychiatr Genet 2005;15:61-65.

12. Swerdlow NR, Sprock J, Light GA, Cadenhead K, Calkins ME, Dobie DJ, et al. Multi-site studies of acoustic startle and prepulse inhibition in humans: initial experience and methodological considerations based on studies by the Consortium on the Genetics of Schizophrenia. Schizophr Res 2007;92:237-251.

13. Tanibuchi Y, Fujita Y, Horio M, Iyo M, Hashimoto K. Effects of quetiapine on dizocilpine-induced prepulse inhibition deficits in mice: possible role of the a a 1 adrenergic receptor. Clin Psychopharmacol Neurosci 2010;8:133-136.

14. Yang Y, Su Y, Guo C, Feng Y, Li J, Si T. A comparison of developmental trajectories of prepulse inhibition between male and female rats. Clin Psychopharmacol Neurosci 2010;8:160-166.

15. Hashimoto K, Fujita Y, Horio M, Hagiwara H, Tanibuchi Y, Iyo M. Effects of cilostazol on dizocilpine-induced hyperlocomotion and prepulse inhibition deficits in mice. Clin Psychopharmacol Neurosci 2010;8:74-78.

16. Cadenhead KS, Carasso BS, Swerdlow NR, Geyer MA, Braff DL. Prepulse inhibition and habituation of the startle response are stable neurobiological measures in a normal male population. Biol Psychiatry 1999;45:360-364.

17. Kumari V, Aasen I, Sharma T. Sex differences in prepulse inhibition deficits in chronic schizophrenia. Schizophr Res 2004;69:219-235.

18. Swerdlow NR, Hartman PL, Auerbach PP. Changes in sensorimotor inhibition across the menstrual cycle: implications for neuropsychiatric disorders. Biol Psychiatry 1997;41:452-460.

19. Aasen I, Kolli L, Kumari V. Sex effects in prepulse inhibition and facilitation of the acoustic startle response: implications for pharmacological and treatment studies. $J$ Psychopharmacol 2005;19:39-45.

20. Abel K, Waikar M, Pedro B, Hemsley D, Geyer M. Repeated testing of prepulse inhibition and habituation of the startle reflex: a study in healthy human controls. $J$ Psychopharmacol 1998;12:330-337.

21. Della Casa V, Höfer I, Weiner I, Feldon J. The effects of smoking on acoustic prepulse inhibition in healthy men and women. Psychopharmacology (Berl) 1998;137:362-368.

22. Swerdlow NR, Auerbach P, Monroe SM, Hartston H, Geyer MA, Braff DL. Men are more inhibited than women by weak prepulses. Biol Psychiatry 1993;34:253-260.

23. Swerdlow NR, Geyer MA, Hartman PL, Sprock J, Auerbach PP, Cadenhead K, et al. Sex differences in sensorimotor gating of the human startle reflex: all smoke? Psychopharmacology (Berl) 1999;146:228-232.

24. Swerdlow NR, Light GA, Cadenhead KS, Sprock J, Hsieh
$\mathrm{MH}$, Braff DL. Startle gating deficits in a large cohort of patients with schizophrenia: relationship to medications, symptoms, neurocognition, and level of function. Arch Gen Psychiatry 2006;63:1325-1335.

25. Kumari V. Sex differences and hormonal influences in human sensorimotor gating: implications for schizophrenia. Curr Top Behav Neurosci 2011;8:141-154.

26. Kumari V, Soni W, Sharma T. Influence of cigarette smoking on prepulse inhibition of the acoustic startle response in schizophrenia. Hum Psychopharmacol 2001;16: 321-326.

27. George TP, Termine A, Sacco KA, Allen TM, Reutenauer $\mathrm{E}$, Vessicchio JC, et al. A preliminary study of the effects of cigarette smoking on prepulse inhibition in schizophrenia: involvement of nicotinic receptor mechanisms. Schizophr Res 2006;87:307-315.

28. Kumari V, Checkley SA, Gray JA. Effect of cigarette smoking on prepulse inhibition of the acoustic startle reflex in healthy male smokers. Psychopharmacology (Berl) 1996; 128:54-60.

29. Rissling AJ, Dawson ME, Schell AM, Nuechterlein KH. Effects of cigarette smoking on prepulse inhibition, its attentional modulation, and vigilance performance. Psychophysiology 2007;44:627-634.

30. Swerdlow NR, Eastvold A, Gerbranda T, Uyan KM, Hartman P, Doan Q, et al. Effects of caffeine on sensorimotor gating of the startle reflex in normal control subjects: impact of caffeine intake and withdrawal. Psychopharmacology (Berl) 2000;151:368-378.

31. Flaten MA, Elden A. Caffeine and prepulse inhibition of the acoustic startle reflex. Psychopharmacology (Berl) 1999;147:322-330.

32. Quednow BB, Kühn KU, Hoenig K, Maier W, Wagner M. Prepulse inhibition and habituation of acoustic startle response in male MDMA ('ecstasy') users, cannabis users, and healthy controls. Neuropsychopharmacology 2004;29: 982-990.

33. Scholes-Balog KE, Martin-Iverson MT. Cannabis use and sensorimotor gating in patients with schizophrenia and healthy controls. Hum Psychopharmacol 2011;26:373-385.

34. Hutchison KE, Swift R. Effect of d-amphetamine on prepulse inhibition of the startle reflex in humans. Psychopharmacology (Berl) 1999;143:394-400.

35. Swerdlow NR, Stephany N, Wasserman LC, Talledo J, Shoemaker J, Auerbach PP. Amphetamine effects on prepulse inhibition across-species: replication and parametric extension. Neuropsychopharmacology 2003;28:640-650.

36. Geyer MA. Are cross-species measures of sensorimotor gating useful for the discovery of procognitive cotreatments for schizophrenia? Dialogues Clin Neurosci 2006;8:9-16.

37. Geyer MA, Krebs-Thomson K, Braff DL, Swerdlow NR. Pharmacological studies of prepulse inhibition models of sensorimotor gating deficits in schizophrenia: a decade in review. Psychopharmacology (Berl) 2001;156:117-154.

38. Braff DL, Geyer MA, Swerdlow NR. Human studies of prepulse inhibition of startle: normal subjects, patient groups, and pharmacological studies. Psychopharmacology (Berl) 2001;156:234-258.

39. Swerdlow NR, Braff DL, Taaid N, Geyer MA. Assessing the validity of an animal model of deficient sensorimotor gating in schizophrenic patients. Arch Gen Psychiatry 1994;51:139-154.

40. Braff DL, Geyer MA. Sensorimotor gating and schizophrenia. Human and animal model studies. Arch Gen Psychiatry 1990;47:181-188.

41. McGhie A, Chapman J. Disorders of attention and per- 
ception in early schizophrenia. Br J Med Psychol 1961; 34:103-116.

42. Braff DL, Geyer MA, Light GA, Sprock J, Perry W, Cadenhead KS, et al. Impact of prepulse characteristics on the detection of sensorimotor gating deficits in schizophrenia. Schizophr Res 2001;49:171-178.

43. Braff DL, Freedman R, Schork NJ, Gottesman II. Deconstructing schizophrenia: an overview of the use of endophenotypes in order to understand a complex disorder. Schizophr Bull 2007;33:21-32.

44. Braff DL, Light GA. The use of neurophysiological endophenotypes to understand the genetic basis of schizophrenia. Dialogues Clin Neurosci 2005;7:125-135.

45. Greenwood TA, Braff DL, Light GA, Cadenhead KS, Calkins ME, Dobie DJ, et al. Initial heritability analyses of endophenotypic measures for schizophrenia: the consortium on the genetics of schizophrenia. Arch Gen Psychiatry 2007;64:1242-1250

46. Turetsky BI, Calkins ME, Light GA, Olincy A, Radant AD, Swerdlow NR. Neurophysiological endophenotypes of schizophrenia: the viability of selected candidate measures. Schizophr Bull 2007;33:69-94.

47. Cadenhead KS, Swerdlow NR, Shafer KM, Diaz M, Braff DL. Modulation of the startle response and startle laterality in relatives of schizophrenic patients and in subjects with schizotypal personality disorder: evidence of inhibitory deficits. Am J Psychiatry 2000;157:1660-1668.

48. Kumari V, Das M, Zachariah E, Ettinger U, Sharma T. Reduced prepulse inhibition in unaffected siblings of schizophrenia patients. Psychophysiology 2005;42:588-594.

49. Anokhin AP, Heath AC, Myers E, Ralano A, Wood S. Genetic influences on prepulse inhibition of startle reflex in humans. Neurosci Lett 2003;353:45-48.

50. Hasenkamp W, Epstein MP, Green A, Wilcox L, Boshoven W, Lewison B, et al. Heritability of acoustic startle magnitude, prepulse inhibition, and startle latency in schizophrenia and control families. Psychiatry Res 2010;178:236243.

51. Cadenhead KS, Geyer MA, Braff DL. Impaired startle prepulse inhibition and habituation in patients with schizotypal personality disorder. Am J Psychiatry 1993;150:18621867.

52. Takahashi $\mathrm{H}$, Iwase $\mathrm{M}$, Canuet $\mathrm{L}$, Yasuda $\mathrm{Y}$, Ohi $\mathrm{K}$, Fukumoto $\mathrm{M}$, et al. Relationship between prepulse inhibition of acoustic startle response and schizotypy in healthy Japanese subjects. Psychophysiology 2010;47:831-837.

53. Kumari V, Toone B, Gray JA. Habituation and prepulse inhibition of the acoustic startle reflex: Effects of smoking status and psychosis-proneness. Personal Individ Differ 1997;23:183-191.

54. Simons RF, Giardina BD. Reflex modification in psychosisprone young adults. Psychophysiology 1992;29:8-16.

55. Swerdlow NR, Filion D, Geyer MA, Braff DL. "Normal" personality correlates of sensorimotor, cognitive, and visuospatial gating. Biol Psychiatry 1995;37:286-299.

56. Takahashi $\mathrm{H}$, Iwase $\mathrm{M}$, Ishii $\mathrm{R}$, Ohi $\mathrm{K}$, Fukumoto $\mathrm{M}$, Azechi $\mathrm{M}$, et al. Impaired prepulse inhibition and habituation of acoustic startle response in Japanese patients with schizophrenia. Neurosci Res 2008;62:187-194.

57. Moriwaki M, Kishi T, Takahashi H, Hashimoto R, Kawashima K, Okochi T, et al. Prepulse inhibition of the startle response with chronic schizophrenia: a replication study. Neurosci Res 2009;65:259-262.

58. Kunugi H, Tanaka M, Hori H, Hashimoto R, Saitoh O, Hironaka N. Prepulse inhibition of acoustic startle in Japanese patients with chronic schizophrenia. Neurosci Res
$2007 \cdot 59 \cdot 23-28$

59. Kumari V, Soni W, Sharma T. Prepulse inhibition of the startle response in risperidone-treated patients: comparison with typical antipsychotics. Schizophr Res 2002;55:139146.

60. Carroll CA, O'Donnell BF, Shekhar A, Hetrick WP. The effects of olanzapine on sensory gating in healthy participants. Schizophr Res 2004;66:187-189.

61. Leumann L, Feldon J, Vollenweider FX, Ludewig K. Effects of typical and atypical antipsychotics on prepulse inhibition and latent inhibition in chronic schizophrenia. Biol Psychiatry 2002;52:729-739.

62. Minassian A, Feifel D, Perry W. The relationship between sensorimotor gating and clinical improvement in acutely ill schizophrenia patients. Schizophr Res 2007;89:225-231.

63. Oranje B, Van Oel CJ, Gispen-De Wied CC, Verbaten MN, Kahn RS. Effects of typical and atypical antipsychotics on the prepulse inhibition of the startle reflex in patients with schizophrenia. J Clin Psychopharmacol 2002;22:359-365.

64. Quednow BB, Wagner M, Westheide J, Beckmann K, Bliesener N, Maier W, et al. Sensorimotor gating and habituation of the startle response in schizophrenic patients randomly treated with amisulpride or olanzapine. Biol Psychiatry 2006;59:536-545.

65. Weike AI, Bauer U, Hamm AO. Effective neuroleptic medication removes prepulse inhibition deficits in schizophrenia patients. Biol Psychiatry 2000;47:61-70.

66. Wynn JK, Green MF, Sprock J, Light GA, Widmark C, Reist $\mathrm{C}$, et al. Effects of olanzapine, risperidone and haloperidol on prepulse inhibition in schizophrenia patients: a double-blind, randomized controlled trial. Schizophr Res 2007:95:134-142.

67. Kishi T, Moriwaki M, Kitajima T, Kawashima K, Okochi $\mathrm{T}$, Fukuo $\mathrm{Y}$, et al. Effect of aripiprazole, risperidone, and olanzapine on the acoustic startle response in Japanese chronic schizophrenia. Psychopharmacology (Berl) 2010; 209:185-190

68. Mackeprang T, Kristiansen KT, Glenthoj BY. Effects of antipsychotics on prepulse inhibition of the startle response in drug-naïve schizophrenic patients. Biol Psychiatry 2002; 52:863-873.

69. Perry W, Feifel D, Minassian A, Bhattacharjie I, Braff DL Information processing deficits in acutely psychotic schizophrenia patients medicated and unmedicated at the time of admission. Am J Psychiatry 2002;159:1375-1381.

70. Duncan E, Szilagyi S, Schwartz M, Kunzova A, Negi S, Efferen T, et al. Prepulse inhibition of acoustic startle in subjects with schizophrenia treated with olanzapine or haloperidol. Psychiatry Res 2003;120:1-12.

71. Braff DL, Swerdlow NR, Geyer MA. Symptom correlates of prepulse inhibition deficits in male schizophrenic patients. Am J Psychiatry 1999;156:596-602.

72. Ludewig K, Vollenweider FX. Impaired sensorimotor gating in schizophrenia with deficit and with nondeficit syndrome. Swiss Med Wkly 2002;132:159-165.

73. Perry W, Braff DL. Information-processing deficits and thought disorder in schizophrenia. Am J Psychiatry 1994; 151:363-367.

74. Wynn JK, Sergi MJ, Dawson ME, Schell AM, Green MF. Sensorimotor gating, orienting and social perception in schizophrenia. Schizophr Res 2005;73:319-325.

75. Kumari V, Peters ER, Fannon D, Premkumar P, Aasen I, Cooke MA, et al. Uncontrollable voices and their relationship to gating deficits in schizophrenia. Schizophr Res 2008;101:185-194.

76. Duncan EJ, Bollini AM, Lewison B, Keyes M, Jovanovic 
$\mathrm{T}$, Gaytan $\mathrm{O}$, et al. Medication status affects the relationship of symptoms to prepulse inhibition of acoustic startle in schizophrenia. Psychiatry Res 2006;145:137-145.

77. Ludewig K, Geyer MA, Vollenweider FX. Deficits in prepulse inhibition and habituation in never-medicated, first-episode schizophrenia. Biol Psychiatry 2003;54:121128.

78. Hammer TB, Oranje B, Fagerlund B, Bro H, Glenthøj BY. Stability of prepulse inhibition and habituation of the startle reflex in schizophrenia: a 6-year follow-up study of initially antipsychotic-naive, first-episode schizophrenia patients. Int J Neuropsychopharmacol 2011;14:913-925.

79. Aggernaes B, Glenthoj BY, Ebdrup BH, Rasmussen H, Lublin H, Oranje B. Sensorimotor gating and habituation in antipsychotic-naive, first-episode schizophrenia patients before and after 6 months' treatment with quetiapine. Int J Neuropsychopharmacol 2010;13:1383-1395.

80. Csomor PA, Yee BK, Feldon J, Theodoridou A, Studerus $\mathrm{E}$, Vollenweider FX. Impaired prepulse inhibition and prepulse-elicited reactivity but intact reflex circuit excitability in unmedicated schizophrenia patients: a comparison with healthy subjects and medicated schizophrenia patients. Schizophr Bull 2009;35:244-255.

81. Vollenweider FX, Barro M, Csomor PA, Feldon J. Clozapine enhances prepulse inhibition in healthy humans with low but not with high prepulse inhibition levels. Biol Psychiatry 2006;60:597-603.

82. Csomor PA, Stadler RR, Feldon J, Yee BK, Geyer MA, Vollenweider FX. Haloperidol differentially modulates prepulse inhibition and p50 suppression in healthy humans stratified for low and high gating levels. Neuropsychopharmacology 2008;33:497-512.

83. Swerdlow NR, Geyer MA, Braff DL. Neural circuit regulation of prepulse inhibition of startle in the rat: current knowledge and future challenges. Psychopharmacology (Berl) 2001;156:194-215.

84. Du Y, Wu X, Li L. Differentially organized top-down modulation of prepulse inhibition of startle. J Neurosci 2011;31:13644-13653.

85. Kumari V, Antonova E, Zachariah E, Galea A, Aasen I, Ettinger U, et al. Structural brain correlates of prepulse inhibition of the acoustic startle response in healthy humans. Neuroimage 2005;26:1052-1058.

86. Kumari V, Fannon D, Geyer MA, Premkumar P, Antonova $\mathrm{E}$, Simmons A, et al. Cortical grey matter volume and sensorimotor gating in schizophrenia. Cortex 2008;44: 1206-1214.

87. Kumari V, Antonova E, Geyer MA, Ffytche D, Williams SC, Sharma T. A fMRI investigation of startle gating deficits in schizophrenia patients treated with typical or atypical antipsychotics. Int J Neuropsychopharmacol 2007; 10:463-477.

88. Kumari V, Gray JA, Geyer MA, ffytche D, Soni W, et al. Neural correlates of tactile prepulse inhibition: a functional MRI study in normal and schizophrenic subjects. Psychiatry Res 2003;122:99-113.

89. Campbell LE, Hughes M, Budd TW, Cooper G, Fulham WR, Karayanidis F, et al. Primary and secondary neural networks of auditory prepulse inhibition: a functional magnetic resonance imaging study of sensorimotor gating of the human acoustic startle response. Eur J Neurosci 2007;26: 2327-2333

90. Hazlett EA, Buchsbaum MS, Zhang J, Newmark RE, Glanton CF, Zelmanova Y, et al. Frontal-striatal-thalamic mediodorsal nucleus dysfunction in schizophrenia-spectrum patients during sensorimotor gating. Neuroimage 2008;42:

\section{4-1177.}

91. Hazlett EA, Buchsbaum MS, Haznedar MM, Singer MB, Germans MK, Schnur DB, et al. Prefrontal cortex glucose metabolism and startle eyeblink modification abnormalities in unmedicated schizophrenia patients. Psychophysiology 1998;35:186-198.

92. Thaker GK. Neurophysiological endophenotypes across bipolar and schizophrenia psychosis. Schizophr Bull 2008; 34:760-773.

93. Roussos P, Giakoumaki SG, Rogdaki M, Pavlakis S, Frangou S, Bitsios P. Prepulse inhibition of the startle reflex depends on the catechol O-methyltransferase Val158Met gene polymorphism. Psychol Med 2008;38:1651-1658.

94. Giakoumaki SG, Roussos P, Bitsios P. Improvement of prepulse inhibition and executive function by the COMT inhibitor tolcapone depends on COMT Val158Met polymorphism. Neuropsychopharmacology 2008;33:3058-3068.

95. Roussos P, Giakoumaki SG, Bitsios P. The dopamine D(3) receptor Ser9Gly polymorphism modulates prepulse inhibition of the acoustic startle reflex. Biol Psychiatry 2008; 64:235-240.

96. Roussos P, Giakoumaki SG, Bitsios P. A risk PRODH haplotype affects sensorimotor gating, memory, schizotypy, and anxiety in healthy male subjects. Biol Psychiatry 2009;65:1063-1070.

97. Liu H, Heath SC, Sobin C, Roos JL, Galke BL, Blundell $\mathrm{ML}$, et al. Genetic variation at the 22q11 PRODH2/ DGCR6 locus presents an unusual pattern and increases susceptibility to schizophrenia. Proc Natl Acad Sci U S A 2002;99:3717-3722.

98. Li T, Ma X, Sham PC, Sun X, Hu X, Wang Q, et al. Evidence for association between novel polymorphisms in the PRODH gene and schizophrenia in a Chinese population. Am J Med Genet B Neuropsychiatr Genet 2004;129B: 13-15.

99. Roussos P, Giakoumaki SG, Adamaki E, Anastasios G, Nikos RK, Bitsios P. The association of schizophrenia risk D-amino acid oxidase polymorphisms with sensorimotor gating, working memory and personality in healthy males. Neuropsychopharmacology 2011;36:1677-1688.

100. Roussos P, Giakoumaki SG, Adamaki E, Bitsios P. The influence of schizophrenia-related neuregulin-1 polymorphisms on sensorimotor gating in healthy males. Biol Psychiatry 2011;69:479-486.

101. Quednow BB, Schmechtig A, Ettinger U, Petrovsky N, Collier DA, Vollenweider FX, et al. Sensorimotor gating depends on polymorphisms of the serotonin- $2 A$ receptor and catechol-O-methyltransferase, but not on neuregulin-1 Arg38Gln genotype: a replication study. Biol Psychiatry 2009;66:614-620.

102. Quednow BB, Kühn KU, Mössner R, Schwab SG, Schuhmacher A, Maier W, et al. Sensorimotor gating of schizophrenia patients is influenced by 5-HT2A receptor polymorphisms. Biol Psychiatry 2008;64:434-437.

103. Quednow BB, Wagner M, Mössner R, Maier W, Kühn KU. Sensorimotor gating of schizophrenia patients depends on Catechol O-methyltransferase Vall58Met polymorphism. Schizophr Bull 2010;36:341-346.

104. Petrovsky N, Quednow BB, Ettinger U, Schmechtig A, Mössner R, Collier DA, et al. Sensorimotor gating is associated with CHRNA3 polymorphisms in schizophrenia and healthy volunteers. Neuropsychopharmacology 2010; 35:1429-1439.

105. Quednow BB, Ettinger U, Mössner R, Rujescu D, Giegling I, Collier DA, et al. The schizophrenia risk allele $C$ of the TCF4 rs9960767 polymorphism disrupts sensorimotor gat- 
ing in schizophrenia spectrum and healthy volunteers. J Neurosci 2011;31:6684-6691.

106. Hong LE, Wonodi I, Stine OC, Mitchell BD, Thaker GK. Evidence of missense mutations on the neuregulin 1 gene affecting function of prepulse inhibition. Biol Psychiatry 2008;63:17-23.

107. Greenbaum L, Levin R, Lerer E, Alkelai A, Kohn Y, Heresco-Levy $\mathrm{U}$, et al. Association of reelin (RELN) single nucleotide polymorphism rs 7341475 with prepulse inhibition in the Jewish Israeli population. Biol Psychiatry 2011;69:e17-e18.

108. Hokyo A, Kanazawa T, Uenishi H, Tsutsumi A, Kawashige $\mathrm{S}$, Kikuyama $\mathrm{H}$, et al. Habituation in prepulse inhibition is affected by a polymorphism on the NMDA receptor $2 B$ subunit gene (GRIN2B). Psychiatr Genet 2010;20:191-198.

109. Hashimoto R, Ohi K, Yasuda Y, Fukumoto M, Yamamori $\mathrm{H}$, Takahashi $\mathrm{H}$, et al. Variants of the RELA gene are associated with schizophrenia and their startle responses. Neuropsychopharmacology 2011;36:1921-1931.

110. Ziermans T, Schothorst P, Magnée M, van Engeland H, Kemner C. Reduced prepulse inhibition in adolescents at risk for psychosis: a 2-year follow-up study. J Psychiatry Neurosci 2011;36:127-134.

111. Quednow BB, Frommann I, Berning J, Kühn KU, Maier $\mathrm{W}$, Wagner M. Impaired sensorimotor gating of the acoustic startle response in the prodrome of schizophrenia. Biol Psychiatry 2008;64:766-773.

112. Cadenhead KS. Startle reactivity and prepulse inhibition in prodromal and early psychosis: effects of age, antipsychotics, tobacco and cannabis in a vulnerable population. Psychiatry Res 2011;188:208-216.

113. Ornitz EM, Guthrie D, Sadeghpour M, Sugiyama T. Maturation of prestimulation-induced startle modulation in girls. Psychophysiology 1991;28:11-20.

114. Ornitz EM, Guthrie D, Kaplan AR, Lane SJ, Norman RJ Maturation of startle modulation. Psychophysiology 1986; 23:624-634.

115. Sobin C, Kiley-Brabeck K, Karayiorgou M. Lower prepulse inhibition in children with the 22 q11 deletion syndrome. Am J Psychiatry 2005;162:1090-1099.

116. Swerdlow NR, Karban B, Ploum Y, Sharp R, Geyer MA, Eastvold A. Tactile prepuff inhibition of startle in children with Tourette's syndrome: in search of an "fMRI-friendly" startle paradigm. Biol Psychiatry 2001;50:578-585.

117. Ornitz EM, Russell AT, Hanna GL, Gabikian P, Gehricke JG, Song D, et al. Prepulse inhibition of startle and the neurobiology of primary nocturnal enuresis. Biol Psychiatry 1999;45:1455-1466.

118. Yuhas J, Cordeiro L, Tassone F, Ballinger E, Schneider A, Long JM, et al. Brief report: Sensorimotor gating in idiopathic autism and autism associated with fragile $X$ syndrome. J Autism Dev Disord 2011;41:248-253.

119. Ornitz EM, Lane SJ, Sugiyama T, de Traversay J. Startle modulation studies in autism. J Autism Dev Disord 1993; 23:619-637.

120. Ashare RL, Hawk LW Jr, Shiels K, Rhodes JD, Pelham WE Jr, Waxmonsky JG. Methylphenidate enhances prepulse inhibition during processing of task-relevant stimuli in attention-deficit/hyperactivity disorder. Psychophysiology 2010;47:838-845.
121. Hawk LW Jr, Yartz AR, Pelham WE Jr, Lock TM. The effects of methylphenidate on prepulse inhibition during attended and ignored prestimuli among boys with attentiondeficit hyperactivity disorder. Psychopharmacology (Berl) 2003;165:118-127.

122. Ornitz EM, Pynoos RS. Startle modulation in children with posttraumatic stress disorder. Am J Psychiatry 1989;146: 866-870.

123. Perry W, Minassian A, Lopez B, Maron L, Lincoln A. Sensorimotor gating deficits in adults with autism. Biol Psychiatry 2007;61:482-486.

124. McAlonan GM, Daly E, Kumari V, Critchley HD, van Amelsvoort T, Suckling J, et al. Brain anatomy and sensorimotor gating in Asperger's syndrome. Brain 2002;125: 1594-1606.

125. Grillon C, Morgan CA 3rd, Davis M, Southwick SM. Effects of experimental context and explicit threat cues on acoustic startle in Vietnam veterans with posttraumatic stress disorder. Biol Psychiatry 1998;44:1027-1036.

126. Grillon C, Morgan CA, Southwick SM, Davis M, Charney DS. Baseline startle amplitude and prepulse inhibition in Vietnam veterans with posttraumatic stress disorder. Psychiatry Res 1996;64:169-178.

127. Lipschitz DS, Mayes LM, Rasmusson AM, Anyan W, Billingslea $\mathrm{E}$, Gueorguieva $\mathrm{R}$, et al. Baseline and modulated acoustic startle responses in adolescent girls with posttraumatic stress disorder. J Am Acad Child Adolesc Psychiatry 2005;44:807-814.

128. Feifel D, Minassian A, Perry W. Prepulse inhibition of startle in adults with ADHD. J Psychiatr Res 2009;43:484489

129. Hanlon MC, Karayanidis F, Schall U. Intact sensorimotor gating in adult attention deficit hyperactivity disorder. Int J Neuropsychopharmacol 2009;12:701-707.

130. Hince DA, Martin-Iverson MT. Differences in prepulse inhibition (PPI) between Wistar and Sprague-Dawley rats clarified by a new method of PPI standardization. Behav Neurosci 2005;119:66-77.

131. Csomor PA, Yee BK, Vollenweider FX, Feldon J, Nicolet $\mathrm{T}$, Quednow $\mathrm{BB}$. On the influence of baseline startle reactivity on the indexation of prepulse inhibition. Behav Neurosci 2008;122:885-900.

132. Scholes KE, Martin-Iverson MT. Disturbed prepulse inhibition in patients with schizophrenia is consequential to dysfunction of selective attention. Psychophysiology 2010; 47:223-235.

133. Kedzior KK, Martin-Iverson MT. Attention-dependent reduction in prepulse inhibition of the startle reflex in cannabis users and schizophrenia patients--a pilot study. Eur J Pharmacol 2007;560:176-182.

134. Hazlett EA, Romero MJ, Haznedar MM, New AS, Goldstein KE, Newmark RE, et al. Deficient attentional modulation of startle eyeblink is associated with symptom severity in the schizophrenia spectrum. Schizophr Res 2007;93:288-295.

135. Dawson ME, Schell AM, Hazlett EA, Nuechterlein KH, Filion DL. On the clinical and cognitive meaning of impaired sensorimotor gating in schizophrenia. Psychiatry Res 2000;96:187-197. 